\title{
Cyclodextrin Complex Formation with Water-Soluble Drugs: Conclusions from Isothermal Titration Calorimetry and Molecular Modeling
}

\author{
Karim S. Shalaby, ${ }^{1,2}$ Muhammad I. Ismail, ${ }^{3}$ and Alf Lamprecht ${ }^{1,4,5}$
}

Received 16 February 2021; accepted 6 May 2021; published online 31 August 2021

\begin{abstract}
Cyclodextrin (CD) complexes are frequently used for enhancing the solubility or absorption of poorly water-soluble drugs. On the contrary, little is known about their complex formation with water-soluble drugs. Here, we have studied the interaction between 2-hydroxypropyl $\beta$-CD (HP $\beta C D)$ and three water-soluble drugs, namely naloxone (NX), oxycodone (OC), and tramadol (TR), by isothermal titration calorimetry (ITC) combined with molecular modeling in view of the potential impact on drug release. The results showed that the complex formation of $\mathrm{HP} \beta C D$ with all three drugs occurs spontaneously. The complexes formed with $\mathrm{NX}$ and $\mathrm{OC}$ were found to be $2 \mathrm{NX}: 1 \mathrm{HP} \beta \mathrm{CD}$ and 3OC:2HP $\beta \mathrm{CD}$, respectively. TR was found to form 2 complexes with $\mathrm{HP} \beta C D$; of 1:2 and 1:1 complexation ratios. The binding of $\mathrm{HP} \beta \mathrm{CD}$ to $\mathrm{NX}$ was greater than to $\mathrm{OC}$ due to the higher hydrophobicity of the structure of the former. Moreover, the binding affinity of HP $\beta C D$ to TR was higher than to $\mathrm{OC}$, which indicated the effect of the higher flexibility of the guest in increasing the binding affinity. In vitro drug release experiments from the various complexes revealed a significant impact of the stoichiometry of the complex on the release profiles. Accordingly, the co-administration of cyclodextrins with water-soluble drugs should be closely monitored, as it may result in unintentional complex formation that can potentially impact the drugs' gastrointestinal absorption.
\end{abstract}

KEY WORDS: isothermal titration calorimetry; molecular modeling; cyclodextrin; water-soluble drugs; tramadol.

\section{INTRODUCTION}

Cyclodextrins (CD) are cyclic macromolecules composed of different numbers of glucose units linked by $\alpha$-1,4-linkage to form a ring structure. Natural CD are composed of 6,7 , or 8 glucose units and called $\alpha-, \beta-$, and $\gamma-C D$, respectively. Due to the limited solubility of unsubstituted natural $\mathrm{CD}$, more soluble derivatives, e.g., 2-hydroxypropyl $\beta$-CD (HP $\beta C D$ ) and sulfobutylether $\beta-\mathrm{CD}$ (SBE $\beta \mathrm{CD})$, have been developed $(1,2)$. Their idealized model shape resembles a truncated cone with a lipophilic central cavity and a hydrophilic outer surface. By virtue of hosting hydrophobic drugs in the central cavity, CD increase the solubility of poorly water-soluble molecules (3-7).

\footnotetext{
${ }^{1}$ Department of Pharmaceutics, Institute of Pharmacy, University of Bonn, Gerhard-Domagk-Str. 3, 53121, Bonn, Germany.

${ }^{2}$ Department of Pharmaceutics and Industrial Pharmacy, Faculty of Pharmacy, Ain Shams University, Cairo, Egypt.

${ }^{3}$ Department of Pharmaceutical Chemistry, Faculty of Pharmacy, The British University in Egypt, Cairo, Egypt.

${ }^{4}$ PEPITE EA4267, University of Burgundy / Franche-Comté, Besançon, France.

${ }^{5}$ To whom correspondence should be addressed. (e-mail: alf.lamprecht@uni-bonn.de)
}

As the drug-CD complex has physicochemical properties different to that of the drug itself, they facilitate the delivery of drugs with poor water solubility or chemical instability, increasing thereby the therapeutic efficiency (6). On the other hand, some CD, particularly those of more hydrophobic nature, have been used to modify or delay the release of some water-soluble drugs, e.g., captopril and metoprolol, to prolong their pharmacological effect (8-10). Accordingly, CD are frequently used as excipients in the pharmaceutical industry (11), mainly for the purpose of enhancing the solubility of water-insoluble drugs. However, limited information is available regarding the binding of $\mathrm{CD}$ with water-soluble drugs, though this could be of great importance in cases where CD and water-soluble actives are concomitantly administered. In such cases, potential interactions therebetween may impact the drug permeability through absorption barriers including but not limited to the gastrointestinal tract.

Various factors have been shown to impact the binding between $C D$ and various drugs. Some are related to the $C D$ molecule itself, including the size of the cavity (13) and the number of water molecules therein (12). Others are related to the guest molecule structure such as molecular length, composition, atomic distribution, and the presence of electronically withdrawing substituents $(13,14)$. Within this 
context, diverse analytical methods have been applied to identify the thermodynamic profile of CD-drug complexation reaction, e.g., ${ }^{1} \mathrm{H}-\mathrm{NMR}$, differential scanning calorimetry (DSC), UV spectroscopy, fluorimetry, isothermal titration calorimetry (ITC), and molecular modeling $(15,16)$.

Among these, ITC has been extensively used for the development of a complete and precise thermodynamic profile of many binding interactions, including the binding between CDs and various lipophilic drugs, where the binding energy was large enough to be measured (17-19). However, the potential of the ITC to analyze less stable binding interaction with low binding energies, e.g., CDs and watersoluble compounds, is yet to be evaluated. Moreover, the curves produced by ITC are sometimes rather complex and cannot be easily interpreted (20). Therefore, the combination of ITC experimental techniques with theoretical perspectives, e.g., molecular modeling, is helpful to interpret ITC complex curves and for developing a three-dimensional illustration of the most stable inclusion complexes (19).

In this study, a combination of ITC and molecular modeling was used to explore and interpret the interaction between $\mathrm{HP} \beta \mathrm{CD}$ and three water-soluble opioid drugs: naloxone hydrochloride (NX), oxycodone hydrochloride (OC), and tramadol hydrochloride (TR). It was demonstrated that, even after dissolution, the unintended interactions between water-soluble drugs and $\mathrm{CD}$ can lead to complex formation. Since CD cannot pass the gastrointestinal barrier, the interaction of such drugs with these molecules might lead to a delay in their absorption in the gastrointestinal tract. Moreover, as the model drugs selected in the current study are structurally related but differ in hydrophobicity and rigidity in their structures (Fig. S1), it was possible to determine the effect of the hydrophobicity and the rigidity of the hydrophilic guest molecule on their affinity to $\mathrm{HP} \beta \mathrm{CD}$.

\section{MATERIALS}

Hydroxypropyl $\beta$-cyclodextrin $(\mathrm{HP} \beta \mathrm{CD})$ was purchased from TCI Deutschland GmbH (Eschborn, Germany). Naloxone $\mathrm{HCl}$, oxycodone $\mathrm{HCl}$, and tramadol $\mathrm{HCl}$ were purchased from Sigma-Aldrich (St. Louis, USA). Regenerated cellulose membrane (molecular weight cutoff $=1000 \mathrm{Da}$ ) was purchased from VWR (Darmstadt, Germany). All other chemicals were of analytical grade.

\section{METHODS}

\section{Isothermal Titration Calorimetry (ITC)}

Aqueous solutions of NX (171.7 mM), OC (257.4 mM), TR (257.4 mM), and HPßCD (10 mM) were cooled and degassed using the Themovac-2 sample degasser and thermostat. ITC measurements were carried out at $298.15 \mathrm{~K}$ (MicroCal VP-ITC® microcalorimeter, Northampton, USA). The degassed drug solution was filled into the injection needle of the device $(299 \mu \mathrm{L})$ and HP $\beta C D$ solution was filled into the cell $(1.43 \mathrm{~mL})$. Titration parameters were set to 58 injections of $5 \mu \mathrm{L}$ of the titrant each for $6 \mathrm{~s}$, and the interval between injections was set at $200 \mathrm{~s}$ and the stirring rate at 310 $\mathrm{rpm}$. The binding isotherm was developed by detection of the heat resulted from each injection. The overall heat was thus measured and used to plot the binding isotherm.

The resulted binding isotherms were analyzed using the fit model of the Origin 5.0® software with the LevenbergMarquardt algorithm. All data analyses were performed after subtraction of the heat of dilution of both the drug and the $\mathrm{HP} \beta C D$ in each case. To this end, the heat resulted from the injection of the drug into water and the injection of water into the HP $\beta C D$ solution was subtracted from that obtained for each injection. Based on the analysis and fitting of the data, the value of stoichiometry $(\mathrm{N})$, the binding constant $(\mathrm{K})$, the change in enthalpy due to binding $(\Delta \mathrm{H})$, the change in Gibb's free energy $(\Delta G)$, and the change in entropy $(\Delta S)$ were developed. $\Delta \mathrm{H}$ and $\Delta \mathrm{S}$ were used to determine the type of binding, whereas $\Delta \mathrm{G}$ was used to determine the spontaneity of the binding.

\section{Molecular Modeling of Drugs with HP $\beta$ CD}

The crystal structure of $\beta-C D$ was downloaded from the Cambridge Structural Database (CSD reference code (BUVSEQ02) (21), and modified using Avogadro software to obtain the molecular structure of 2-HPBCD at C6 $(22,23)$. Generalized Amber force field (GAFF) was used to minimize the resulting structure (24). Ligand structures were constructed using MarvinSketch (25) and minimized using MMFF94s force field (26). All minimization runs were implemented via Open Babel software with 10,000 steps using the steepest descent algorithm (27). Molecular docking was carried out using AutoDock Vina software (28) implemented through PyRx GUI (29). All figures were generated using UCSF Chimera (30). Through these methods, the binding of two molecules of $\mathrm{HP} \beta \mathrm{CD}$ together to form a dimer was simulated and compared to the binding of $\mathrm{HP} \beta C D$ to each of the different drug molecules. The formation of complexes of different stoichiometries was also studied to determine the most stable complex between HP $\beta C D$ and each drug.

\section{The Release Profile of NX, OC, and TR from Complexes}

The dissociation and release of NX, OC, and TR from complexes were analyzed by means of vertical Franz cells (SES GmbH, Bechenheim, Germany) with a regenerated cellulose membrane (molecular weight cutoff $=1000 \mathrm{Da}$ ) and an acceptor compartment filled with $8 \mathrm{~mL}$ of a buffered solution of $\mathrm{pH}$ 2. Solutions of NX, OC, and TR, or their complexes with HP $\beta C D$ (NX-HP $\beta C D$, OC-HP $\beta C D$, or TR$\mathrm{HP} \beta C D$ ) were added to the donor compartment. As the complexes are spontaneously formed in water, the complexes' solutions were prepared by mixing of the pure drug solution with solution of HP $\beta C D$. The mixture was then maintained for $20 \mathrm{~min}$ to achieve an equilibrium. A total of $300 \mu \mathrm{L}$ of $\mathrm{NX}$ or its complex with HP $\beta C D$, or $200 \mu \mathrm{L}$ of OC, TR, or their resultant complexes, was added to the donor compartment. The concentrations of NX, OC, and TR in all solutions were $320 \mathrm{mM}, 360 \mathrm{mM}$, and $12 \mathrm{mM}$, respectively. In all cases, the experiment was carried out under a controlled temperature of $37^{\circ} \mathrm{C}$ (JULABO GmbH, Seelbach, Germany) and in triplicate. At predetermined time points, samples $(500 \mu \mathrm{L})$ each were withdrawn from each cell and replaced by a fresh buffer. 
The samples were analyzed using HPLC (Agilent Technologies, Waldbronn, Germany) by modification of previously reported methods (31-33). Briefly, $\mathrm{NX} \mathrm{HCl}$ was quantified using a C8 column LiChrospher 60 RP Select B-5 $\mu$ (CS-Chromatographie, Merck) at $60^{\circ} \mathrm{C}$. The mobile phase was composed of buffer ( $\mathrm{pH} 2)$ and methanol (85:15). The flow rate and injection volume were $1 \mathrm{~mL} \mathrm{~min}^{-1}$ and $10 \mu \mathrm{L}$, respectively. The detection wavelength was $230 \mathrm{~nm}$. Limit of detection (LOD) and limit of quantification (LOQ) were calculated as $330.38 \mu \mathrm{g} / \mathrm{mL}$ and $1002.53 \mu \mathrm{g} / \mathrm{mL}$, respectively. The quantification of $\mathrm{OC} \mathrm{HCl}$ was performed analogously, using a C8 column LiChrospher 60 RP Select B-5 $\mu$ (CSChromatographie, Merck), with the same mobile phase, and at the same flow rate and temperature. Peaks were detected at $230 \mathrm{~nm}$. LOD was $15.56 \mu \mathrm{g} / \mathrm{mL}$ and LOQ was $47.14 \mu \mathrm{g} / \mathrm{mL}$.

TR $\mathrm{HCl}$, on the other hand, was quantified using a LiChrospher® RP-18 HPLC Column $(5 \mu \mathrm{m}$ particle size, $\mathrm{L} \times$ I.D. $15 \mathrm{~cm} \times 3.2 \mathrm{~mm})($ CS-Chromatographie, Merck) at room temperature. The mobile phase consisted of phosphate buffer (pH 6.0):methanol (40:60). The flow rate was set to $1.0 \mathrm{~mL}$ $\min ^{-1}$ and the detection wavelength was $270 \mathrm{~nm}$. Under such conditions, the LOD and LOQ were equal to $22.62 \mu \mathrm{g} / \mathrm{mL}$ and $68.54 \mu \mathrm{g} / \mathrm{mL}$, respectively.

\section{RESULTS}

\section{NX and HP $\beta C D$}

Following the subtraction of the dilution heat of both compounds, the binding isotherm originating from the titration of $\mathrm{NX}(171.7 \mathrm{mM})$ and $\mathrm{HP} \beta \mathrm{CD}(10 \mathrm{mM})$ comprises three phases (Fig. 1a). In the first phase, small but increasing amounts of heat evolved (exothermic peaks), until a maximum was reached. Afterward, the amount of heat produced tended to decrease steadily giving the curve a linear appearance with a nearly constant slope (the second phase). In the third phase, the heat produced tended to be constant and the curve started to form a plateau. This curve resembles the normal sigmoid binding isotherms except in the first phase, in which there are small, yet increasing in size, exothermic peaks. The curve was fitted to the one set of identical site model after omitting the first phase (Fig. 1) and the binding parameters were developed (Table I).

Based on the calculated values (Table I), the stoichiometry of the binding of NX to HP $\beta C D$ is 2:1. The values of $\Delta \mathrm{H}$ and $\Delta \mathrm{G}$ are negative and the value of enthalpy is smaller than that of entropy $(|\Delta \mathrm{H}|<|\mathrm{T} \Delta \mathrm{S}|)$.

The docking score $(\Delta \mathrm{G})$ related to the docking of NX into $\mathrm{HP} \beta C D(-7 \mathrm{kcal} / \mathrm{mol})$ is more negative than representing the docking of one $\mathrm{HP} \beta \mathrm{CD}$ molecule into another $(-4.0 \mathrm{kcal} / \mathrm{mol})$. Docking another molecule of NX into NX-HP $\beta C D$ receptor molecule gives a binding energy of $-5.0 \mathrm{kcal} / \mathrm{mol}$ which indicates a favorable binding of a second NX molecule to the NX-HP $\beta C D$ complex (Fig. 2).

\section{$O C$ and HP $\beta C D$}

Similar to the case of NX, the binding isotherm originating from the titration of $\mathrm{OC}(257.4 \mathrm{mM})$ and $\mathrm{HP} \beta \mathrm{CD}$ $(10 \mathrm{mM})$ (following the subtraction of the dilution heat of OC and $\mathrm{HP} \beta C D$ ) is triphasic. Hence, the net heat evolved in the first phase was also omitted before fitting of the curve to the one set of identical site model (Fig. 1b), which enabled calculating the values of the binding parameters $(\mathrm{N}, \mathrm{K}, \Delta \mathrm{H}$, and $\Delta S$ ) developed. From these values, $T \Delta S$ and $\Delta G$ were calculated (Table I). The stoichiometry of the binding of OC to $\mathrm{HP} \beta C D$ is about 1.5 which suggests that a $1.5: 1$ ratio is energetically suitable; e.g., 3 molecules of OC bind to 2 molecules of $\mathrm{HP} \beta C D$. As in the case of NX, the values of $\Delta \mathrm{H}$ and $\Delta G$ are negative, and the value of enthalpy is smaller than that of entropy $(|\Delta \mathrm{H}|<|\mathrm{T} \Delta \mathrm{S}|)$.

OC was docked into HP $\beta C D$ to determine its binding affinity, where the calculated docking score of $-6.9 \mathrm{kcal} / \mathrm{mol}$ supported the experimentally performed isotherm. To determine the ability of OC to form complexes with $\mathrm{HP} \beta C D$, a stepwise docking approach was applied. This was performed by docking different molecules of OC and $\mathrm{HP} \beta C D$ to previously formed complex in each step, e.g., a second molecule of OC to the OC-HP $\beta C D$ complex, a third OC molecule to the OC-OC-HP $\beta C D$ complex, and finally docking HP $\beta C D$ to the OC-OC-OC-HP $\beta C D$ complex, and so on (Fig. 3). The calculated docking score in $\mathrm{kcal} / \mathrm{mol}$ was developed in each binding step (Table II).

\section{TR and HP $\beta C D$}

After the subtraction of the dilution heat of TR and $\mathrm{HP} \beta C D$, the binding isotherm originating from the titration of the TR $(257.4 \mathrm{mM})$ and $\mathrm{HP} \beta \mathrm{CD}(10 \mathrm{mM})$ comprises 4 phases (Fig. 1c). The first phase consists of large, but getting smaller, exothermic peaks. The second phase shows exothermic peaks, which increase in size, and is followed by a phase of exothermic peaks, which get smaller. Finally, the curve starts to form a plateau-like behavior, which represents the fourth phase. The whole curve was fitted to the three sequential binding site model of the Origin $5.0{ }^{\circledR}$ software as shown in Fig. 1c (the red curve), and the values of fitting parameters $(\mathrm{Kn}, \Delta \mathrm{Hn}$, and $\Delta \mathrm{Sn})$ for every interaction and, subsequently, the values of $\Delta \mathrm{Sn}$ and $\Delta \mathrm{Gn}$ were calculated (Table I). It should be noted that $\mathrm{n}$ indicates the first, the second, or the third interaction.

To determine the stoichiometry of the binding of TR with $\mathrm{HP} \beta C D$, the data obtained from the first phase only was fitted to the one set of identical site model and the resultant stoichiometry indicated that the complex was composed of 2 molecules of $\mathrm{HP} \beta \mathrm{CD}$ and one molecule of TR. On the contrary, when the third and last phase of the curve was fitted to the one set of identical site model, the resultant stoichiometry indicated the presence of a 1:1 complex molecule (data not shown).

Here again, computational calculation of binding affinity $(\Delta G)$ was carried out using molecular docking, and the predicted binding affinity in $\mathrm{kcal} / \mathrm{mol}$ of each docking complex is shown in Table III. Additionally, the predicted TR-HP $\beta C D$ complexes are shown in Fig. 4.

\section{The Release Profile of NX, OC, and TR from Complexes}

The release of the drugs from their complexes with $\mathrm{HP} \beta C D$ into the acceptor compartment showed a more delayed profile than the release of the corresponding free drugs (Fig. 5a-c). Comparing the release profile of complexes 

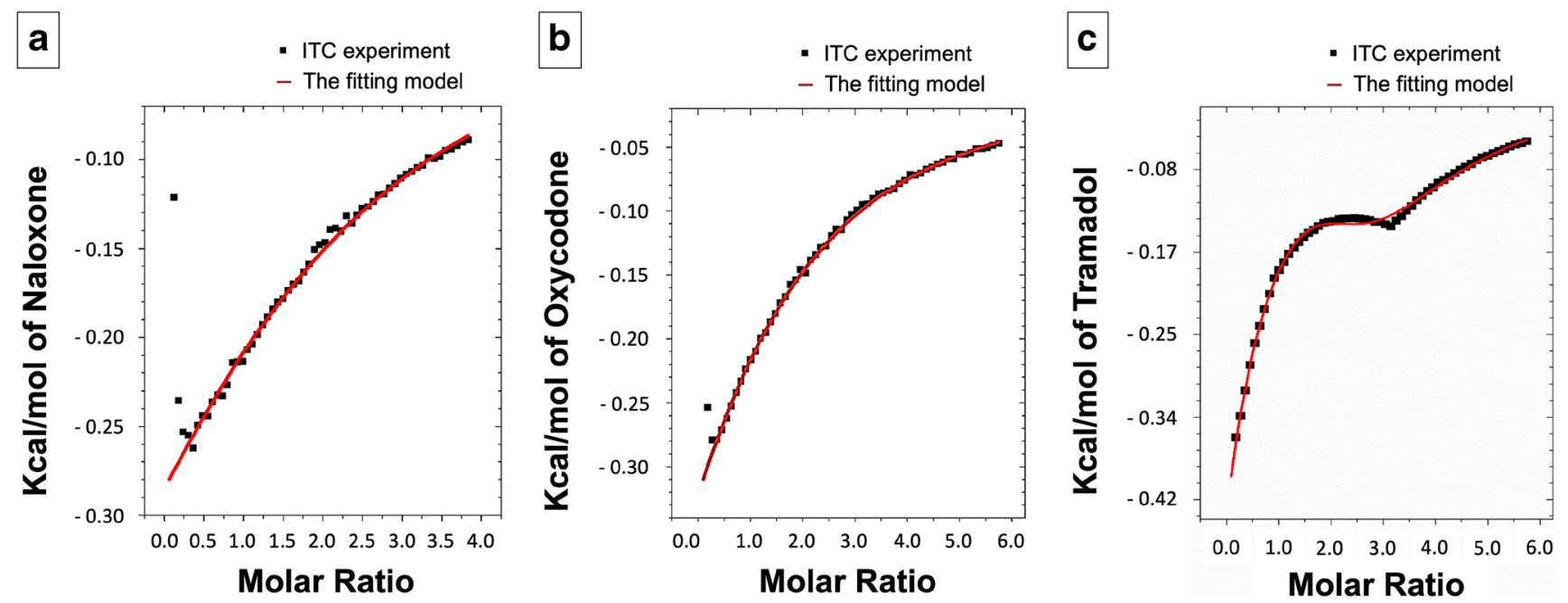

Fig. 1. The binding isotherm of the binding of a NX, b OC, and $\mathbf{c}$ TR with HP $\beta C D$ after subtraction of the dilution heat of the drugs and $\mathrm{HP} \beta \mathrm{CD}$ then fitting

that have different stoichiometry, it was found that the delay in drug release is dependent on complex stoichiometry (Fig. 5d).

\section{DISCUSSION}

ITC analyses of the NX-HP $\beta C D$ complexes yielded a triphasic curve (Fig. 1a). In this case, rather than high nearly equal exothermic peaks expected during the first phase of the normal isotherm (sigmoid curve), small, but becoming larger, exothermal peaks are observed. A potential explanation for this phenomenon is the presence of $\mathrm{HP} \beta \mathrm{CD}$ as dimers in the solution, which is in line with an earlier report (34). Consequently, the observed peaks in the first phase are related to the dissociation of $\mathrm{HP} \beta C D$ dimers (endothermic) and the formation of NX-HP $\beta C D$ complex (exothermic). This explains the initial small, but increasing in size, exothermic peaks which continued until all HP $\beta C D$ dimers are separated into single molecules. Thereafter, NX binds to $\mathrm{HP} \beta C D$ monomers resulting in a decreasing pattern of peaks (phase 2), as the number of free $\mathrm{HP} \beta \mathrm{CD}$ molecules decreases. Once a 2:1 binding is fully achieved, further addition of NX cannot result in any subsequent binding, accounting for the observed reduced steepness of the slope. Since the net heat developed in the first phase is not purely related to the binding between $\mathrm{HP} \beta \mathrm{CD}$ and $\mathrm{NX}$, it was omitted before fitting the curve to the single-site model and the subsequent calculation of the binding parameters. The score calculated for the docking of NX into $\mathrm{HP} \beta \mathrm{CD}(-7.0$ $\mathrm{kcal} / \mathrm{mol})$ is more negative than that of $\mathrm{HP} \beta \mathrm{CD}$ molecule docked into another $\mathrm{HP} \beta C D$ molecule $(-4.0 \mathrm{kcal} / \mathrm{mol})$, which supports the hypothesis that NX displaces one molecule of $\mathrm{HP} \beta \mathrm{CD}$ in $\mathrm{HP} \beta \mathrm{CD}$ dimer to make a more stable complex with HP $\beta C D$. The docking of another molecule of $\mathrm{NX}$ into NX-HP $\beta \mathrm{CD}$ is favored as indicated by the favorable binding energy $(-5.0 \mathrm{kcal} / \mathrm{mol})$. Besides, the sum of these energies together was more favorable than the binding energy of two HP $\beta C D$ molecules to form a dimer which supports the experimental results of NX forming a complex with $\mathrm{HP} \beta \mathrm{CD}$ in a 2:1 ratio.

We also aimed to investigate the effect of drug hydrophobicity on its complex formation with $\mathrm{HP} \beta \mathrm{CD}$. To this end,

Table I. The Thermodynamic Parameters for the Binding of Naloxone HCl, Oxycodone $\mathrm{HCl}$, and Tramadol $\mathrm{HCl}$ with 2-Hydroxypropyl $\beta$ Cyclodextrin After Subtraction of the Dilution Heat of the Drugs and 2-Hydroxypropyl $\beta$-Cyclodextrin then Fitting

\begin{tabular}{|c|c|c|c|c|}
\hline Parameter & Naloxone & Oxycodone & Tramadol & Unit \\
\hline $\mathrm{N}$ & $2.036 \pm 0.02$ & $1.46 \pm 0.08$ & & \\
\hline$\Delta \mathrm{H}_{1}$ & $-523.8 \pm 14.42$ & $-759.50 \pm 28.99$ & $-443.97 \pm 26.08$ & $\mathrm{kcal} / \mathrm{mol}$ \\
\hline $\mathrm{K}_{1}$ & $56.78 \pm 2.01$ & $48.50 \pm 2.14$ & $814.17 \pm 89.18$ & $\mathrm{M}^{-1}$ \\
\hline $\mathrm{T} \Delta \mathrm{S}_{1}$ & $1868.80 \pm 35.42$ & $1539.80 \pm 2.74$ & $3524.13 \pm 60.88$ & $\mathrm{kcal} / \mathrm{Mol}$ \\
\hline$\Delta \mathrm{G}_{1}$ & $-2392.6 \pm 20.99$ & $-2299.30 \pm 26.25$ & $-3968.10 \pm 62.68$ & $\mathrm{kcal} / \mathrm{mol}$ \\
\hline $\mathrm{K}_{2}$ & & & $352.73 \pm 16.02$ & $\mathrm{M}^{-1}$ \\
\hline$\Delta \mathrm{H}_{2}$ & & & $129.74 \pm 39.87$ & $\mathrm{kcal} / \mathrm{mol}$ \\
\hline $\mathrm{T} \Delta \mathrm{S}_{2}$ & & & $3604.63 \pm 16.60$ & $\mathrm{kcal} / \mathrm{mol}$ \\
\hline$\Delta \mathrm{G}_{2}$ & & & $-3474.90 \pm 27.07$ & $\mathrm{kcal} / \mathrm{mol}$ \\
\hline $\mathrm{K}_{3}$ & & & $60.17 \pm 6.07$ & $\mathrm{M}^{-1}$ \\
\hline$\Delta \mathrm{H}_{3}$ & & & $-810.43 \pm 20.11$ & $\mathrm{kcal} / \mathrm{mol}$ \\
\hline $\mathrm{T} \Delta \mathrm{S}_{3}$ & & & $1614.88 \pm 41.34$ & $\mathrm{kcal} / \mathrm{mol}$ \\
\hline$\Delta \mathrm{G}_{3}$ & & & $-2425.31 \pm 61.18$ & $\mathrm{kcal} / \mathrm{mol}$ \\
\hline
\end{tabular}



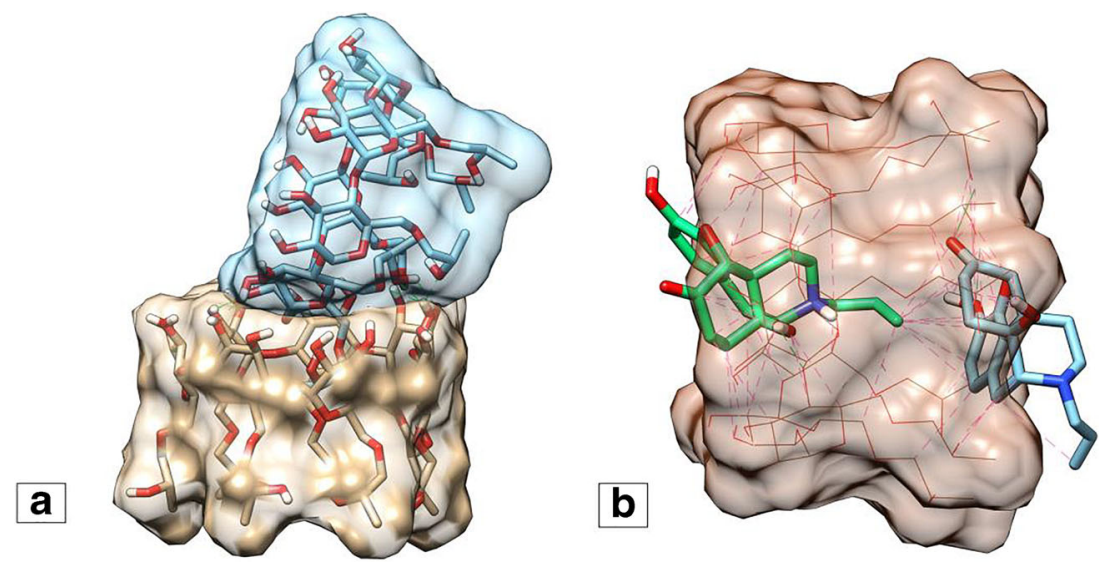

Fig. 2. a $H P \beta C D$ dimer predicted by molecular docking. b NX-HP $\beta C D$ complex with ratio 2:1 predicted by molecular docking. The two NX molecules are depicted in green (front) and blue (back). The hydrogen bonds are in green dashed lines and the hydrophobic contacts are in magenta

we included OC within the experiments, as it is structurally similar to NX but is less hydrophobic in nature. ITC and molecular docking results show that 3 molecules of OC bind to 2 molecules of $\mathrm{HP} \beta C D$. The lower stoichiometry value indicates a lower affinity of $\mathrm{HP} \beta \mathrm{CD}$ to OC when compared to $\mathrm{NX}$. This is also supported by the lower value of the binding constant $(\mathrm{K})$ and the absolute value of Gibb's free energy $(\Delta \mathrm{G})$ for OC than for NX.

Another goal within the context of the current study was to investigate the effect of the difference in structural rigidity of the drug upon its complex formation with $\mathrm{HP} \beta \mathrm{CD}$. Accordingly, we also included TR within the experiments, as it possesses structural similarity with $\mathrm{OC}$ but less rigid due to a lower number of rings in its structure. The ITC experiment yielded a complex interaction curve composed of 4 phases (Fig. 1c). We hypothesized that phase 1 involves the binding of one TR molecule with two molecules of $\mathrm{HP} \beta \mathrm{CD}$ to form the 1:2 complex as previously reported (16) and as detected by fitting this phase to a single binding site model (data not

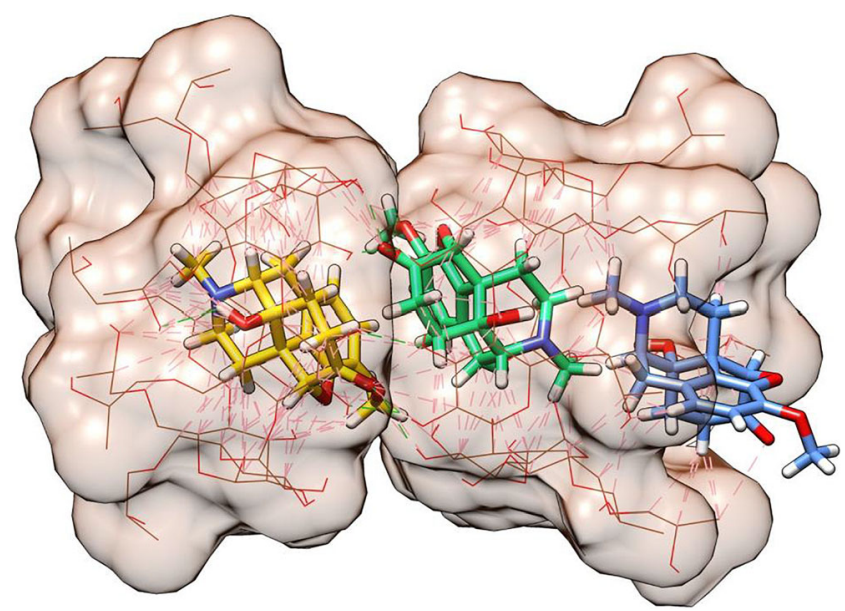

Fig. 3. Complex of $3 \mathrm{OC}: 2 \mathrm{HP} \beta \mathrm{CD}$ predicted by stepwise docking. Initial $\mathrm{HP} \beta \mathrm{CD}$ molecule (khaki) on the right, used as a receptor, and the docked HPßCD (khaki) on the left. First, second, and third OC docked molecules are shown as blue (right), green (middle), and gold (left) sticks, respectively. The hydrogen bonds are as green dashed lines, and the hydrophobic contacts are in magenta shown). Though this binding has probably resulted in the production of a high amount of heat, a part of this heat has been seemingly absorbed for dissociation of TR dimers as well as HP $\beta C D$ dimers. Hence, the net exothermic peaks are smaller in value than they should be. In phase 2, further addition of TR up to a definite concentration leads to the dissociation of one molecule of $\mathrm{HP} \beta \mathrm{CD}$ from the complex 1TR:2HP $\beta C D$ (endothermic), followed by the binding of the released molecule of HP $\beta C D$ with another molecule of TR (exothermic). Since the heat absorbed for complex dissociation is lower than the heat evolved in new complex formation, the net result has been manifested as exothermic peaks. These peaks become larger as the number of 1TR:2HP $\beta C D$ molecules continuously decreased. This phase continues until all 1TR:2HP $\beta C D$ complex molecules are dissociated. After that, new molecules of TR added in phase 3 continue to interact with the remaining free molecule of $\mathrm{HP} \beta \mathrm{CD}$ to form the 1:1 complex. This accounts for exothermic peaks, which become smaller due to the decreasing amount of free $\mathrm{HP} \beta \mathrm{CD}$ remaining in the cell. Lastly, in phase 4, addition of TR led to no further interaction, as all $\mathrm{HP} \beta \mathrm{CD}$ molecules have been complexed, giving rise to the curve having a near plateau shape.

Computational calculation of the binding affinity between TR and HP $\beta C D$ was used to interpret the ITC behavior of TR-HP $\beta C D$ complexation. Based on these investigations, we hypothesize that the high exothermic interactions observed in phase 1 are the result of the binding of one molecule of TR to two molecules of $\mathrm{HP} \beta \mathrm{CD}$ with predicted $\Delta \mathrm{G}=-8.0 \mathrm{kcal} / \mathrm{mol}$. The heat evolved from this exothermic interaction exceeds the endothermic energy required to dissociate one TR dimer and one $\mathrm{HP} \beta \mathrm{CD}$ dimer $(+2.9$ and $+4.0 \mathrm{kcal} / \mathrm{mol}$, respectively). Therefore, endothermic and exothermic energies have resulted in a net $\Delta G=|8.0|$ $-|2.9|-|4.0|=|1.1| \mathrm{kcal} / \mathrm{mol}$, which means that the net result is an exotherm but less in value than the normal exotherm expected from the formation of the 1TR:2HP $\beta C D$ complex. In phase 2, the combined endotherm required to dissociate one TR dimer $(+2.9 \mathrm{kcal} / \mathrm{mol})$ and one $\mathrm{HP} \beta \mathrm{CD}$ molecule from 1TR:2HP $\beta C D(+3.1 \mathrm{kcal} / \mathrm{mol})$ is comparable to the exotherm released due to the formation of the 1TR:1HP $\beta C D$ 
Table II. Binding Affinities (kcal/mol) for the Building up Process of OC-HPßCD 3:2 Complex Through Stepwise Docking

\begin{tabular}{|c|c|c|c|}
\hline Docking step & Ligand & Receptor & Docking score $(\mathrm{kcal} / \mathrm{mol})$ \\
\hline 1 & $\mathrm{OC}$ & $\mathrm{HP} \beta \mathrm{CD}$ & -6.9 \\
\hline 2 & $\mathrm{OC}$ & OC-HP $\beta C D$ complex & -5.9 \\
\hline 3 & $\mathrm{OC}$ & OC-OC-HP $\beta$ CD complex & -5.1 \\
\hline 4 & $\mathrm{HP} \beta \mathrm{CD}$ & OC-OC-OC-HP $\beta C D$ complex & -3.9 \\
\hline
\end{tabular}

$O C$ oxycodone $\mathrm{HCl}, H P \beta C D$ 2-hydroxypropyl $\beta$-cyclodextrin

complex (- $6.0 \mathrm{kcal} / \mathrm{mol})$, which gives phase 2 a nearly plateau shape. In phase 3 , the exotherm released due to the formation of the 1TR:1HP $\beta C D$ complex is dominant and endows phase 3 its exothermic behavior.

Both the binding affinity and docking score of TR to 2 molecules of $\mathrm{HP} \beta \mathrm{CD}$ are higher than to 1 molecule of HP $\beta C D$. This could be attributed to the higher number of hydrophobic interactions between one molecule of TR and 2 molecules of $\mathrm{HP} \beta C D$, when compared to that between one molecule of TR and one molecule of HP $\beta C D$. During the formation of the 1:2 complex, the TR molecule has the ability to bind to the most favorable binding positions in 2 molecules of $\mathrm{HP} \beta C D$, resulting in a maximum number of hydrophobic interactions. Therefore, it has high binding affinity and docking score. However, the limited number of hydrophobic interaction sites in 1 molecule of $\mathrm{HP} \beta C D$ during 1:1 complex formation accounts for the lower binding affinity and docking score.

Based on the combination of ITC and molecular modeling, it can be detected that TR forms two types of complexes with $\operatorname{HP} \beta C D$ (1:2 and 1:1). This explains the contradicting results obtained from the two previously performed studies $(15,16)$. In the first study, the complexation of TR with $\beta-C D$ was examined using ${ }^{1} \mathrm{H}-\mathrm{NMR}$ and UV and fluorescence spectroscopy, where the inclusion of TR inside the cavity of $\beta-C D$ did not affect the absorbance values, but increased the intensity of its fluorescence emission in highly concentrated TR solutions only. On the other hand, it did not affect the fluorescence emission from solutions of lower concentrations that do not normally suffer from a reduction in fluorescence due to self-quenching (15). The selfquenching behavior of TR reported in that study may support our assumption that TR exists as dimers in concentrated solutions. The ratio for the complex formation that was concluded from that study was 1:1. This was contradicting to the results of a second study, in which the inclusion complex of $\beta-C D$ with TR was investigated by ${ }^{1} \mathrm{HNMR}$, FT-IR, DSC, and scanning electron microscope (SEM), where the complex was reported to be of $2 \beta-C D$ and 1 TR molecules (16).

In cases of all three hydrophilic drugs investigated herein, the binding is due to the hydrophobic interaction with the hydrophobic cavity of HP $\beta C D$. This is accompanied by the release of a water molecule from the cyclodextrin cavity, which is represented by the high entropy and lower enthalpy of interactions as well as the high number of hydrophobic contacts between $\mathrm{HP} \beta \mathrm{CD}$ and the drugs (magenta dashed lines in 3D figures of the complexes). Accordingly, the presence of more hydrophobic groups in high numbers increases the affinity of the water-soluble guest molecule to the $\mathrm{CD}$ molecule. Additionally, higher flexibility of the guest molecule enhances its ability to properly position its hydrophobic groups into the cavity, strengthening thereby the hydrophobic interactions. This is confirmed by the higher binding constant $(\Delta \mathrm{G})$ and the binding affinity $(\mathrm{K})$ of TR to $\mathrm{HP} \beta C D$ compared with the other two drugs, which signifies a lower structural rigidity to increase its affinity to form complex with CD.

It should be also noted that all the binding interactions studied here were exothermic as indicated by the negative values of $\Delta \mathrm{H}$. Surprisingly, the values of $\Delta \mathrm{G}$ were also negative demonstrating that the binding interactions of $\mathrm{CD}$, even with water-soluble molecules, are spontaneous and favored. This means that the presence of CD together with these water-soluble drugs in the same solution will result in spontaneous complex formation without the need for special preparation procedures. This finding has various implications, as it can impact drug formulations in many different ways. For instance, drug availability and permeation, as demonstrated here with in vitro drug release tests, can be strongly modified. As observed in this case, the diffusion of NX, OC, and TR through a dialysis membrane was generally slower when the drug was in a complex form. Furthermore, the release of TR from the 1:2 TR-HPßCD complex was slower when compared to the 1:1 complex. This may be due to the stronger

Table III. Docking Experiments Showing the Receptor and the Ligand in Each Docked Complex, and the Resulting Binding Affinity in $\mathrm{kcal} / \mathrm{mol}$

\begin{tabular}{|c|c|c|c|}
\hline Docked complex & Ligand & Receptor & Docking score $(\mathrm{kcal} / \mathrm{mol})$ \\
\hline Tramadol-tramadol & Tramadol & Tramadol & -2.9 \\
\hline HP $\beta C D-H P \beta C D$ & $\mathrm{HP} \beta \mathrm{CD}$ & $\mathrm{HP} \beta \mathrm{CD}$ & -4.0 \\
\hline Tramadol-HP $\beta C D-H P \beta C D$ & Tramadol & HP $\beta C D-H P \beta C D$ complex & -8.0 \\
\hline HP $\beta C D$-tramadol-HP $\beta C D$ & $\mathrm{HP} \beta \mathrm{CD}$ & Tramadol-HP $\beta C D$ complex & -3.1 \\
\hline Tramadol-HP $\beta C D$ & Tramadol & $\mathrm{HP} \beta \mathrm{CD}$ & -6.0 \\
\hline
\end{tabular}



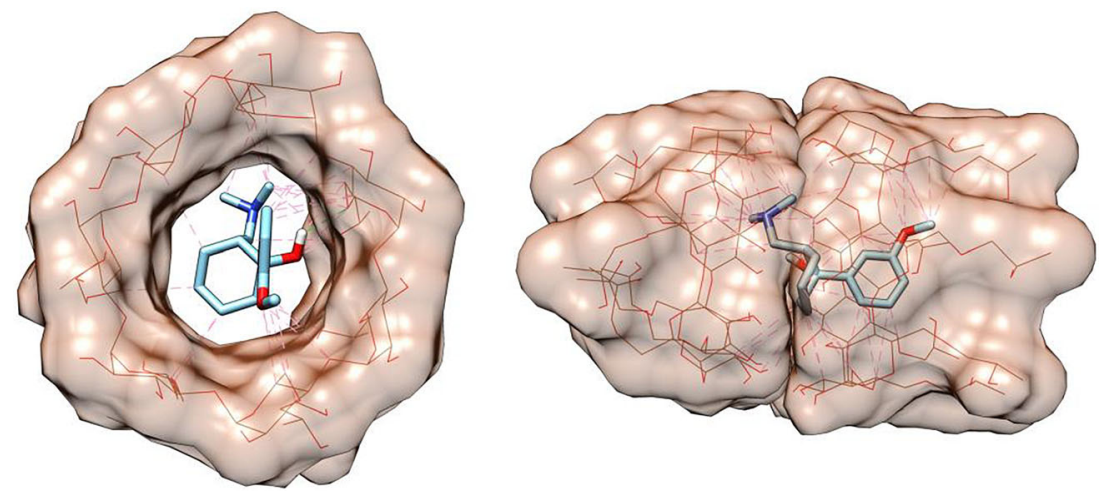

Fig. 4. $3 \mathrm{D}$ view of TR (blue sticks) docked in a monomer (left) and a dimer (right) of $\mathrm{HP} \beta \mathrm{CD}$ (brown wire). The hydrogen bonds are as green dashed lines, and the hydrophobic contacts are in magenta

hydrophobic interactions of TR with the 2 molecules of $\mathrm{HP} \beta C D$ resulting from the cage structure, formed by 2 molecules of $\mathrm{HP} \beta \mathrm{CD}$, which may hinder the escape of the TR molecule from the complex. Although the OC-HPBCD complex shows the same cage structure, the delay in release was not profound as in TR-HP $\beta C D$ complex 1:2. This can be attributed to that the binding affinity of $\mathrm{HP} \beta C D$ to $\mathrm{OC}$ is lower than its binding affinity to TR and that the number of OC molecules in the complex is higher than the number of $\mathrm{HP} \beta \mathrm{CD}$ molecules. Consequently, not all OC molecules are strongly entrapped within the cavity of the cage structure of the two HP $\beta C D$ molecules, and can thus dissociate from the complex more easily. This assumption is supported by comparing the release profile of all the complexes studied (Fig. 5d). In all cases, higher number of $\mathrm{HP} \beta C D$ molecules in the complex is associated with a longer delay of the drug release therefrom.

As drug-CD complexes are known not to pass through the gastrointestinal barrier (35), the release studies were performed with a semipermeable membrane allowing the passage of the drugs, but not the CDs or the complexes. Given the instantaneous complex formation, the gastrointestinal absorbance of these drugs will be slower in the presence of CDs. As a result, the therapeutic efficacy, especially in case of the investigated opioid drugs, might be strongly affected. The water-soluble drugs were selected to demonstrate that complexes with CDs can be formed even after complete dissolution. Despite the complexes' water solubility, they may delay the absorption of the drugs, as the rate of drug dissociation from CDs might be the speed limiting step. This

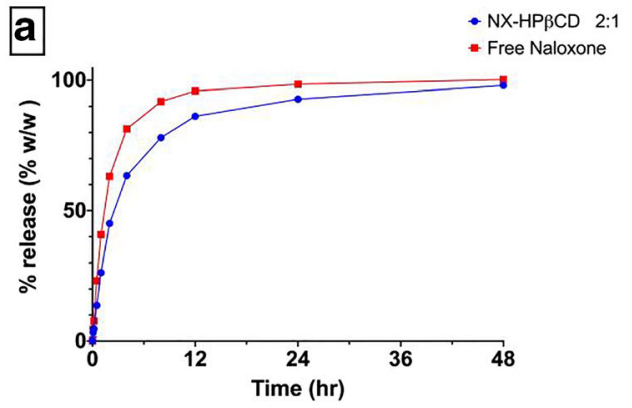

a

c

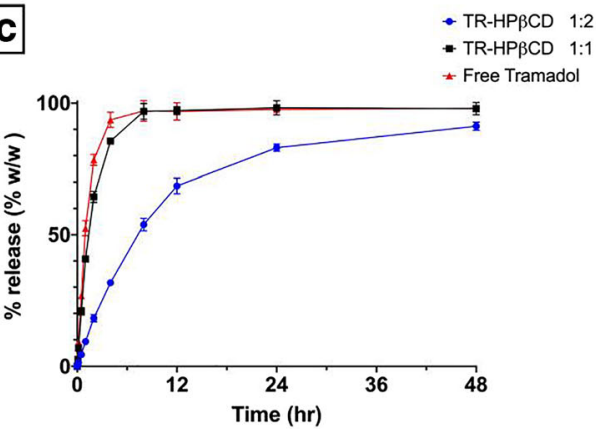

OC-HPBCD $3: 2$
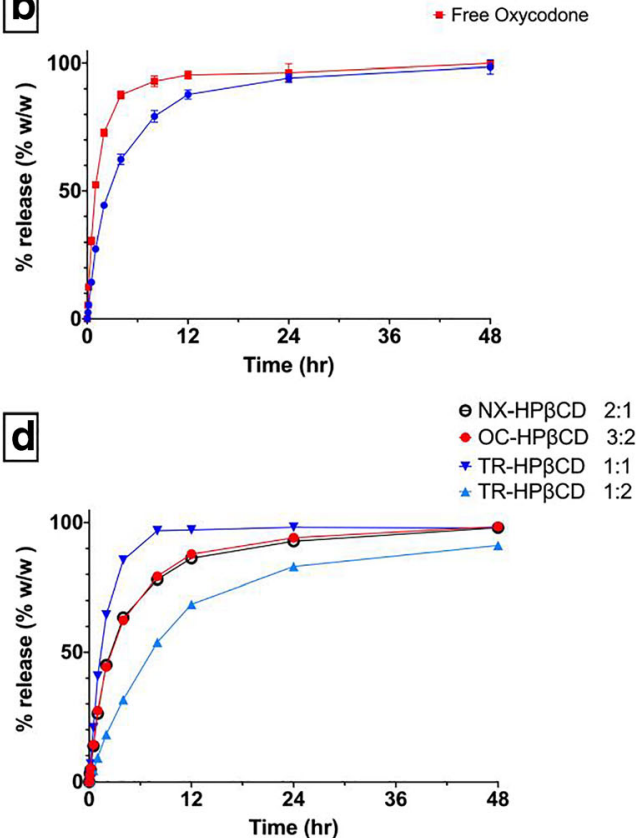

Fig. 5. The release profile of $\mathrm{NX} \mathbf{a}, \mathrm{OC} \mathbf{b}$, and TR $\mathbf{c}$ and their complexes with $\mathrm{HP} \beta \mathrm{CD}$ in a buffer of $\mathrm{pH} 2$. d The release profile of all complexes 
becomes more relevant when considering that the gastric transit time is limited, and that a complete drug dissociation and release was in this case achieved in $48 \mathrm{~h}$. In case of the drugs used as potent analgesics, such as TR and OC, time is a very important factor in increasing the quality of treatment. Accordingly, the concomitant administration of these drugs and other dosage forms containing $\mathrm{CD}$ as excipients may lead to an inadvertent delay in the desired analgesic effect. Therefore, the example presented here highlights the importance of an in-depth analysis of the potential drug-excipient interactions, which can be integrated as a screening step before or during the formulation development of pharmaceutical products.

\section{CONCLUSION}

This study confirms the ability of CD to spontaneously form complexes with water-soluble drugs and the impact of such a complex formation on the drugs' release behavior. ITC results and molecular modeling indicate that $\mathrm{CD}$ have higher binding affinity to drugs with higher hydrophobicity and structural flexibility. Additionally, complex formation was shown to retard the drug permeation across semipermeable membranes, as the drug first needs to dissociate from the complex. The rate of permeation was proportional to the ratio of $\mathrm{CD}$ molecules in the complex. Taken together, the current study highlights the potential of implementing a combination of ITC and molecular modeling for the detection of incompatibilities between water-soluble drugs and $\mathrm{CD}$, which have been beyond serious considerations by now. Further studies are surely needed to detail whether this is a general formulation obstacle or remains limited in effect and to a small number of hydrophilic actives.

\section{SUPPLEMENTARY INFORMATION}

The online version contains supplementary material available at https://doi.org/10.1208/s12249-021-02040-8.

\section{ACKNOWLEDGEMENTS}

Karim Shalaby would like to thank the Egyptian Ministry of Higher Education and the German Academic Exchange Service (DAAD) (91613363) for their financial support. The authors gratefully acknowledge Dr. Maryam A Shetab Boushehri for proofreading this article.

\section{AUTHOR CONTRIBUTION}

Karim S. Shalaby: theoretical formalism, hypothesis generation, methodology, analytic calculations, data analysis, investigation, original draft writing. Muhammad I. Ismail: molecular modeling, computational calculations, molecules visualization. Alf Lamprecht: project administration, resources, concept formulation, supervision, editing and review.

\section{FUNDING} DEAL.

\section{DECLARATIONS}

Conflict of Interest The authors declare no competing interests.

Open Access This article is licensed under a Creative Commons Attribution 4.0 International License, which permits use, sharing, adaptation, distribution and reproduction in any medium or format, as long as you give appropriate credit to the original author(s) and the source, provide a link to the Creative Commons licence, and indicate if changes were made. The images or other third party material in this article are included in the article's Creative Commons licence, unless indicated otherwise in a credit line to the material. If material is not included in the article's Creative Commons licence and your intended use is not permitted by statutory regulation or exceeds the permitted use, you will need to obtain permission directly from the copyright holder. To view a copy of this licence, visit http://creativecommons.org/licenses/by/4.0/.

\section{REFERENCES}

1. Davis ME, Brewster ME. Cyclodextrin-based pharmaceutics: past, present and future. Nat Rev Drug Discov. 2004;3:1023-35.

2. Carneiro SB, Duarte FÍC, Heimfarth L, Quintans JDSS, QuintansJúnior LJ, Júnior VFDV, et al. Cyclodextrin-drug inclusion complexes: in vivo and in vitro approaches. Int J Mol Sci. 2019;20:1-23.

3. Astray G, Gonzalez-Barreiro C, Mejuto JC, Rial-Otero R, Simal-Gándara J. A review on the use of cyclodextrins in foods. Food Hydrocoll. 2009;23:1631-40.

4. Jansook P, Ogawa N, Loftsson T. Cyclodextrins: structure, physicochemical properties and pharmaceutical applications. Int J Pharm. 2018;535:272-84.

5. Gidwani B, Vyas A. A comprehensive review on cyclodextrinbased carriers for delivery of chemotherapeutic cytotoxic anticancer drugs. Biomed Res Int. 2015;2015:1-15. https:// doi.org/10.1155/2015/198268.

6. Saokham P, Muankaew C, Jansook P, Loftsson T. Solubility of cyclodextrins and drug/cyclodextrin complexes. Molecules. 2018;23:1161.

7. Stella VJ, He Q. Cyclodextrins. Toxicol Pathol. 2008;36:30-42.

8. Ikeda Y, Motoune S, Marumoto A, Sonoda Y, Hirayama F, Arima H, Uekama K (2002) Effect of 2-hydroxypropyl- $\beta$ cyclodextrin on release rate of metoprolol from ternary metoprolol/2-hydroxypropyl- $\beta$ - cyclodextrin/ethylcellulose tablets. Journal of Inclusion Phenomena. 2002;44:141-144.

9. Ikeda Y, Kimura K, Hirayama F, Arima H, Uekama K. Controlled release of a water-soluble drug, captopril, by a combination of hydrophilic and hydrophobic cyclodextrin derivatives. J Control Release. 2000;66:271-80.

10. Salústio PJ, Pontes P, Conduto C, Sanches I, Carvalho C, Arrais $\mathrm{J}$, et al. Advanced technologies for oral controlled release: cyclodextrins for oral controlled release. AAPS PharmSciTech. 2011;12:1276-92.

11. Conceição J, Adeoye O, Cabral-Marques HM, Lobo JMS. Cyclodextrins as excipients in tablet formulations. Drug Discov Today. 2018;23:1274-84.

12. da Rocha Neto AC, de Oliveira da Rocha AB, Maraschin M, Di Piero RM, Almenar E. Factors affecting the entrapment efficiency of $\beta$-cyclodextrins and their effects on the formation of inclusion complexes containing essential oils. Food Hydrocoll. 2018;77:509-23.

13. Jankowski CK, Lamouroux C, Jiménez-Estrada M, Arseneau S, Wagner BD. Factors affecting the formation of 2:1 host:guest inclusion complexes of 2 -[(R-phenyl)amine $]-1,4-$ 
naphthalenediones (PAN) in $\beta$ - and $\gamma$-cyclodextrins. Molecules. 2016;21(11):1568 https://doi.org/10.3390/molecules21111568.

14. Alvira E. Molecular dynamics study of the factors influencing the $\beta$-cyclodextrin inclusion complex formation of the isomers of linear molecules. J Chem. 2017;2017:1-9. https://doi.org/ $10.1155 / 2017 / 6907421$

15. Zidane S, Maiza A, Bouleghlem H, Fenet B, Chevalier Y. Inclusion complex of tramadol in $\beta$-cyclodextrin enhances fluorescence by preventing self-quenching. J Incl Phenom Macrocycl Chem. 2019;93:253-64.

16. Anton Smith A, Manavalan R, Kannan K, Rajendiran N. Spectral characteristics of tramadol in different solvents and $\beta$ cyclodextrin. Spectrochim Acta A Mol Biomol Spectrosc. 2009;74:469-77.

17. Stepniak A, Erdenebayar B, Biernacka M, Buczkowski A, Zavodnik L, Zavodnik I, et al. Calorimetric studies of $\alpha$ cyclodextrin inclusion complexes with carbendazim and thiabendazole. Phys Chem Liq. 2020:1-8. https://doi.org/10.1080/ 00319104.2020.1737693.

18. Ondo D. Thermodynamic study on complexation of long-chain fatty acid anions with $\alpha$-cyclodextrin in water. J Mol Liq. 2020;311:113172.

19. Xavier-Júnior FH, Tavares CT, Rabello MM, Hernandes MZ, Bezerra BP, Ayala AP, et al. Elucidation of the mechanism of complexation between oncocalyxone $\mathrm{A}$ and cyclodextrins by isothermal titration calorimetry and molecular modeling. J Mol Liq. 2019;274:165-72.

20. Archer WR, Schulz MD. Isothermal titration calorimetry: practical approaches and current applications in soft matter. Soft Matter. 2020;16:8760-74.

21. Betzel C, Saenger W, Hingerty BE, Brown GM. Topography of cyclodextrin inclusion complexes, part 20. Circular and flip-flop hydrogen bonding in. beta.-cyclodextrin undecahydrate: a neutron diffraction study. J Am Chem Soc. 1984;106:7545-57.

22. Hanwell MD, Curtis DE, Lonie DC, Vandermeerschd T, Zurek E, Hutchison GR. Avogadro: an advanced semantic chemical editor, visualization, and analysis platform. J Cheminformatics. 2012;4:17.

23. Avogadro: an open-source molecular builder and visualization tool. Version 1.2.0. http://avogadro.cc/

24. Wang J, Wolf RM, Caldwell JW, Kollman PA, Case DA. Development and testing of a general Amber force field. J Comput Chem. 2004;25:1157-74.
25. Cherinka B, Andrews BH, Sánchez-Gallego J, et al. Marvin: A tool kit for streamlined access and visualization of the SDSS-IV MaNGA data set. Astron J. 2019;158:74

26. Halgren TA. MMFF VI. MMFF94s option for energy minimization studies. J Comput Chem. 1999;20:720-9.

27. O'Boyle NM, Banck M, James CA, Morley C, Vandermeersch T, Hutchison GR. Open Babel: an open chemical toolbox. J Cheminformatics. 2011;3:33.

28. Trott O, Olson AJ. Software news and update AutoDock Vina: Improving the speed and accuracy of docking with a new scoring function, efficient optimization, and multithreading. J Comput Chem. 2010;31:455-61.

29. Dallakyan S, Olson AJ. Small-molecule library screening by docking with PyRx. Methods Mol Biol. 2015;1263:243-50.

30. Pettersen EF, Goddard TD, Huang CC, Couch GS, Greenblatt DM, Meng EC, et al. UCSF Chimera - a visualization system for exploratory research and analysis. J Comput Chem. 2004;25:1605-12.

31. Chandra P, Rathore A, Lohidasan S, Mahadik K. Application of HPLC for the simultaneous determination of aceclofenac, paracetamol and tramadol hydrochloride in pharmaceutical dosage form. 2012;80:337-51.

32. Kozak J, Rabiskova M, Lamprecht A. Silk fibroin as a novel alcohol-resistant excipient for sustained-release tablet formulation. AAPS PharmSciTech. 2019;20:1-11.

33. Gil-Alegre ME, Barone ML, Torres-Suárez AI. Extraction and determination by liquid chromatography and spectrophotometry of naloxone in microparticles for drug-addiction treatment. J Sep Sci. 2005;28:2086-93.

34. Inghelbrecht S, Ryzhakov A, Stappaerts J, et al. Self-assembly of cyclodextrins and their complexes in aqueous solutions. J Pharm Sci. 2016;105:2556-69.

35. Jones DS, Dressman JB, Loftsson T, Moya-Ortega MD, AlvarezLorenzo C, Concheiro A. Pharmacokinetics of cyclodextrins and drugs after oral and parenteral administration of drug/cyclodextrin complexes. J Pharm Pharmacol. 2016;68:544-55.

Publisher's Note Springer Nature remains neutral with regard to jurisdictional claims in published maps and institutional affiliations. 